\title{
ADVANCES IN CULTURAL TOURISM: TWO EXAMPLES FROM THE EMIRATE OF ABU DHABI (UAE)
}

\author{
Adriaan DE MAN* \\ United Arab Emirates University (UAEU), Department of Tourism and Heritage, \\ PO Box 15551, Al Ain, United Arab Emirates, e-mail: adriaandeman@uaeu.ac.ae
}

Citation: De Man, A. (2020). ADVANCES IN CUlTURAL TOURISM: TWO EXAMPLES FROM THE EMIRATE OF ABU DHABI (UAE). GeoJournal of Tourism and Geosites, 31(3), 1027-1033. https://doi.org/10.30892/gtg.31314-537.

\begin{abstract}
The aim of this paper is analyzing desert remoteness as a potential competitive advantage for cultural tourism. In the emirate of Abu Dhabi, at least two destinations can capitalize on the perception of insularity, while at the same time offering high levels of comfort and accessibility. This text seeks to provide an overview on the matter, and enters a conceptual dimension about the singularity of remoteness, as a complement rather than an opposition to urban centrality. To do so, the insular condition is applied to an island and an oasis in analogous terms, through a heuristic-guided methodology.
\end{abstract}

Key words: Heritage tourism, remoteness, aridity, sustainability, economic growth

\section{INTRODUCTION}

Tourism development for extra-urban Arabian destinations is, first and foremost, a complex academic topic, as it relates to such a huge geographical diversity that an island or desert condition often becomes secondary, even in terms of access itself. The United Arab Emirates' immediate neighbours are working towards similar products: Saudi Arabia has been investing heavily in heritage tourism, within its Vision 2030 strategy (Abuhjeeleh, 2019), whilst Oman equally aims at enhancing its GDP through tourism primarily based on its landscape assets (Al Hasni, 2019). In the particular case of the United Arab Emirates, and its global strategic options in diversification, Abu Dhabi Economic Vision 2030 pinpoints the centrality of tourism, with the Department of Culture and Tourism (DCT) investing in a Strategy to Preserve and Protect Cultural Heritage, taken as a fundamental resource. Infrastructures do matter a lot in the commodification of cultural and natural heritage; in the UAE, bridges, roads or affordable airline services provide mainstream, consumer-centric accessibility, heavily focused on Dubai but with easy logistical ramifications across the rest of the country. Success in destination management depends on variables such as value for money, public infrastructures, and perceptions on safety and security, perhaps more than the strict condition of a water- or desertlocked landscape. What does, however, add complexity to, say, an island product is the sometimes quite marketable, exotic landscape, on the one hand, and the additional logistic challenges in the service supply, on the other. Comparable issues do emerge in certain desert or severely arid destinations (Webb, 2002; Allan, 2016), where an escapism factor linked to both tourism cognition and geographic isolation become quintessential determinants, often susceptible to climate variation (Abed and Matzarakis, 2018).

The case studies below do exhibit some of these features, in what can be understood perhaps as mature and successful branding stories. Al Ain's regional location, historical relevance as a major oasis, and the setting of Jebel Hafeet as a massive, dominant mountain in an otherwise flat landscape, does provide the city with a definite uniqueness. From a geographical standpoint, the island of Saadiyat is however no different from the several neighbouring ones. Contrary to Dubai, Abu Dhabi is an island itself, and (sea) water is ubiquitous throughout the city. The distinctiveness Saadiyat offers lays above all in its size, proximity to Abu Dhabi, and the very long stretch of pristine beaches along which hotels have chosen to develop. Every other resource is man-made and stems from a masterplan that seeks to create a huge cultural district, intertwined with residential and leisure areas. The island's original identity, which includes some archaeological sites and more recent settlement, has transitioned into a very recognizable label, intensified by the idea of water-confined exclusivity.

As one of the largest islands of Abu Dhabi, Saadiyat has very rapidly grown into the capital's main cultural centre. It aggregates different districts, some of which residential and hospitality-based, having become internationally known as the location of the Louvre, and the almost finalized Guggenheim and Zayed National museums. The entire project is to be concluded before the Dubai Expo 2020, at a 1h drive from Saadiyat. Although easily accessible by bridges, the circumstance of being an island provides the area with a clear distinctiveness, leading to both technical challenges and marketable opportunities. Still in the emirate of Abu Dhabi, yet representing an inland desert location, the Cultural Sites of Al Ain were inscribed on UNESCO's World Heritage List in 2011. They are composed of several non-contiguous components providing cohesion to a unique cultural landscape, topographically oriented by Jebel Hafeet, on the border with Oman. One of the sites is an archaeological park some $15 \mathrm{~km}$ from the city centre, with important remains of different periods. Tombs in Hili and Jebel Hafeet underwent a sequence of excavations and restorations, and very recent fieldwork in the same area has documented more detailed chronologies. The site is overseen by the Abu Dhabi Department of Culture and Tourism, which is responsible for its conservation and management.

\section{MATERIAL AND METHODS}

The underlying intricacy of the text may be approached using a heuristic methodology, building on an inductive, comparative analysis. Indeed scholarship on both desert and island studies evolved towards coherent, interdisciplinary subjects, yet remain an academic focus, more than necessarily a discipline, as explicitly assumed in the opening paper of the fairly recent Island St udies Journal (Baldacchino, 2006), or an exploratory study on desert tourism (Tremblay, 2006). The fact today remains that literature on the subject is unsurprisingly varied, and at the same time case-based. Syntheses on what really configures commonalities of "islandness" or "desert tourism" are much less available. Pungetti (2016) edited a book on the characteristics of European seascapes, and Graci and Dodds (2010) had produced a study on a number of real-life problems and solutions for sustainable island tourism, through analysing size,

\footnotetext{
${ }^{*}$ Corresponding author
} 
isolation, and resource limitations. The authors propose multi-stakeholder partnerships as a way forward; a devil's advocate might ask how this fundamentally differs from a mainland destination. Indeed, remoteness (Sharpley, 2012) or ultraperipheral circumstan ces (Parra López and Calero García, 2006) constitute a common denominator in many a study on islands, with the more recent literature increasingly deep-diving into notions such as sociocultural and economical sustainability (Carlsen and Butler, 2011; Agrusa et al., 2010; Modica and Uysal, 2016; Podhorodecka, 2018). But they apply to continental regions too, where remote regions try to cope with asymmetries through similar invigorating strategies in heritage and tourism (De Man, 2016). In more than just a strict metaph orical sense, oases may be understood as islands too, surrounded by sand deserts or arid lands. Elsewhere in such particular geographies (Sauvage and Gámez, 2013), adaptive cultural policies are fundamental in articulating commodification with cultural heritage conservation.

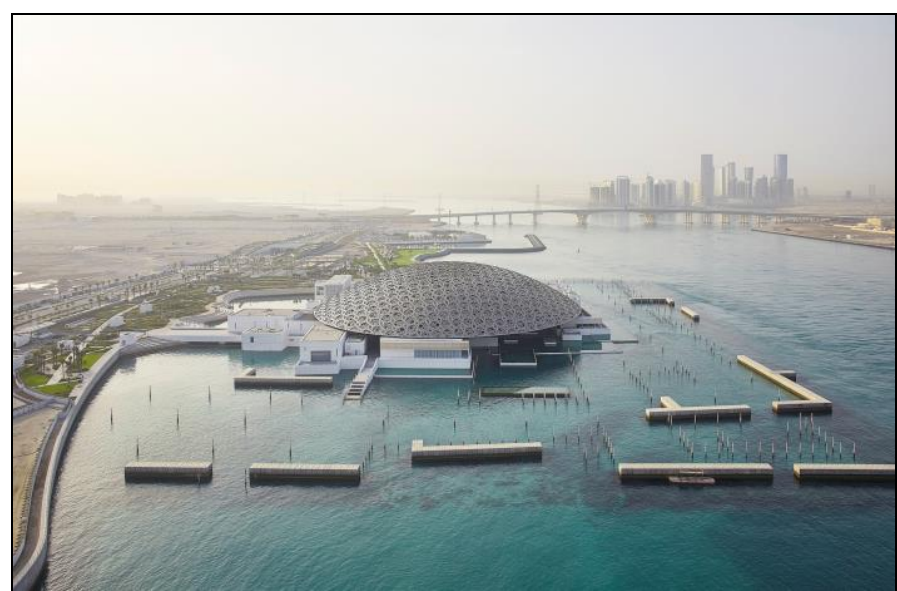

Figure 1. Saadiyat: Louvre Abu Dhabi @ Abu Dhabi

Department of Culture and Tourism (Photography: Hufton and Crow)

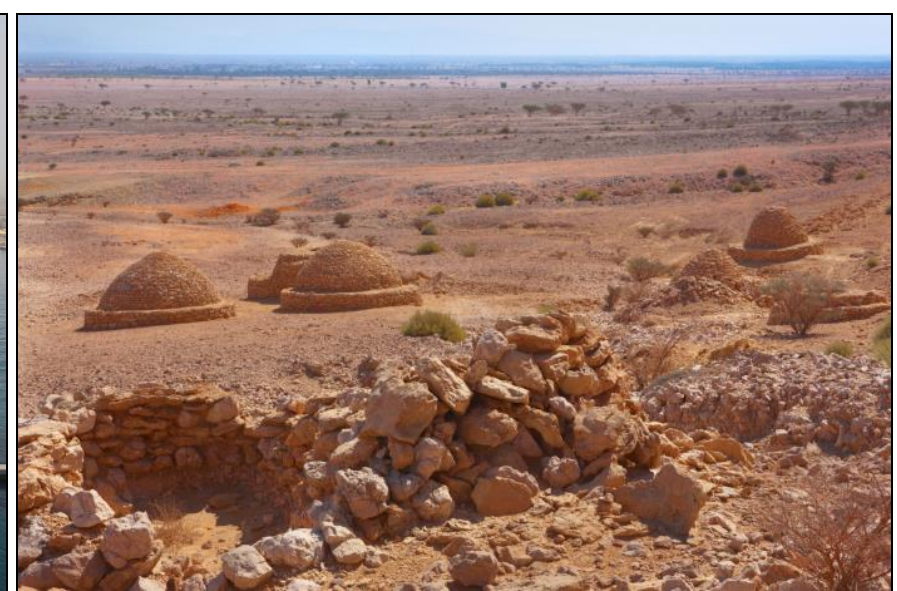

Figure 2. Al Ain: Hafeet tombs ( $)$ Abu Dhabi Department of Culture and Tourism, Photography: (Petra and Erik Hesmerg )

What both island and desert destinations can capitalize on is their high profile iconic attractions, which may obstruct both academic and market approaches to the subject. In other words, the centric tourist expects a plethora of references to caravan trekkin g, oasis life, palm trees, camels and dunes when planning a trip to what is taken as a desert product. Correspondingly, the conceptual framework for island tourism is also frequently warm-water focused, concerned with peripheral monoculture or small State building (McLeod, 2018), which does not work equally well for many other destinations. A second dimension in this paper tackles what can be called cultural or heritage tourism at both Saadiyat and Al Ain, and the investment in museums and other cultural centres. A qualitative heurist ics approach (Kleining and Witt, 2000) may refine the identification of potential advantages specific to this reality, using a dialectical instead of a linear, narrative procedure. In practice, this causes a sequence of open, back and forth queries on the subject of remoteness. Gnoth and Matteucci (2014) do follow such an approach to question how to identify heuristics in research on the tourism experience. The y may be seen as non-perfect, practical rules linking an outcome to the specific context in which a selection was made. In the cultural tourism industry, the multiplicity of individual empirical experiences make deterministic, all-or-nothing heuristics impractical; probabilistic ones, on the other hand, collide with a heterogeneity so large it challenges formal representations, although this may be mitigated through computation (Van Middelkoop et al., 2003). In order to assess the applicability of remoteness as a theoretical factor, focus is laid on the heuristic value criterion, which can be used as a synonym for utility in tourism and hospitality research (Sorokina and Wang, 2018).

\section{THE TERRITORIAL FRAMEWORK}

It has been pointed out that the heritage-related economy is somewhat segmented and, on occasion, may suffer from hypermodernity, but it substantially forms a consistent, integrated product (De Man, 2018) that is straightforwardly marketable. The notion of human and physical geography influencing culture and its commodification, which on its turn can serve as a stimulus for economic growth, is found in many technical reports. An issue here is acquiring and processing metrics, as most impacts are induced ones. Furthermore, economists and anthropologists do have rather distinct notions of what culture actually entails (Khawar, 2016) for tourism economics, both theoretically and methodologically (De Jong, 2015). These limitations fundamentally apply to the study cases below.

Saadiyat, the also named Happiness island, is located at less than one kilometer from Abu Dhabi island, and consists of a very low mass of 27 square $\mathrm{km}$, counting on $30 \mathrm{~km}$ of total coastline. In order to frame the current circumstances, a case of oral history may be illustrative as a starting point. A local man recalls Saadiyat as an island without electricity or drinking water, in the 1970s: "My mother and grandmother would go to Abu Dhabi to get food and water and I would go with them, but nobody used too much because we would clean our clothes and wash in the sea. (...) As well as the Sha'biyat [government building], there was a school house, a small police station and a hospital, but this was only open for two hours at a time and was only for first aid" (Leech, 2016). Much has changed in the last decade. The fairly recent urban development on Saadiyat was conceived to accommodate cultural institutions as well as high class leisure and residential areas. This was planned through the creation of three districts: Culture, Beach, and Marina. General setups should be implemented by 2020, at an initial estimated cost of US\$27 billion. The original 2007 press release referred to the original masterplan, including six districts, twenty-nine hotels, including a 7-star unit, three marinas with about one thousand berths, two golf courses, and a planned resident population of about 150.000 people. It was envisaged, in a broad sense, as a cultural enclave, pertaining different national goals, from local pride to global museum integration (Elsheshtawy, 2012). On its turn, Al Ain, the Garden City, integrates this same resolution in a specific way. It lays at about $145 \mathrm{~km}$ from Abu Dhabi, and even slightly closer to Dubai, currently on a land border with the sultanate of Oman but historically a central oasis hub located mid-distance between the Gulf coastline of Abu Dhabi and Dubai (and the pre-contemporary dominant port of Julfar, mod. Ras Al Khaimah), and the Indian ocean, on the Peninsula's east coast (for early modern trade dynamics see De Man, 2019a). The royal family is also from the region; the city is the birthplace of the nation's Founding Father, Sheikh Zayed, and home to the oldest and largest federal university, as well as several large hospitals. For these reasons, Al Ain is a key historical, population and political centre that however may go unnoticed to the average tourist visiting the coastal metropoles. Its urban configuration stems from a planned social effort, which accelerated in 1986 with the creation of new residential districts (Haggag and Hadjri, 2005), further linking and providing urban 
density to what had originally been a cultural landscape of six oases, their palm groves and irrigation systems, as well as their traditional buildings, all of which have been conserved and restored in the last few decades (Yildirim and El-Masri, 2010).

The emirate's tourism potential was outlined two decades ago (Sharpley, 2002), when international visitor numbers in this region were not yet close to the current ones. It is interesting that this analysis considered Al Ain as Abu Dhabi's key leisure tou rism asset; much has changed since, including some of the threats at the time (e.g. fragmentation of the industry, limited supply in Abu Dhabi city, reduced shopping facilities, and so forth). The situation has, to a certain extent, switched, with the capital concentrating international travel. Cultural heritage tourism has indeed become a major driver for the emirate of Abu Dhabi, and the wider UAE (Exell, 2017). Currently, the flagship component is the Louvre Abu Dhabi, an institution branded as a universal museum. The Department of Culture and Tourism, which owns and operates the Louvre in collaboration with French authorities, indicates a strategic ambition to intensify the contribution of tourism to the GDP in the next years (DTC 2018), and Abu Dhabi seeks to enter the top five most visited citie s by 2030, a scenario in which the Saadiyat museums are expected to function as a tourist magnet (Koşak, n/d). Apart from the Louvre, the construction of a Guggenheim museum is finally kicking off, as well as a Zayed national and a maritime museum. Another major cultural hub on Saadiyat is the New York University campus, offering plenty of activities (museum events, exhibitions, concerts, conferences). These are network-based, with educational, artistic and other outreach programs such as roadshows linking institutions, especially across Abu Dhabi and Dubai. This implementation of international branches has been called a neoliberal restructuring of the arts and culture (Derderian, 2013), and can be discussed in anthropological and social ways; what matters to this text is their specific relevance in facilitating tourist flows to distinct zones of consumption, that is, to Saadiyat island. Also worth noticing is that any cul tural postcolonial stance would be fundamentally inappropriate here, as correctly pointed out by Poulin (2010): the UAE is certainly not an underdeveloped country, and France is not imposing but rather exporting its know-how. As far as the other cultural hubs are concerned, the Manarat Al Saadiyat is a community centre bringing people together through movie screenings, a weekly Open Mic, photography competitions, workshops, and the Art Studio lecturing a remarkable 9.914 people in its first year. The two museums in the making have been active as well, despite not being completed yet. Both Zayed National Museum and the Guggenheim Abu Dhabi have been running several programs, the former with a focus on national identity, and the latter on contemporary art (DCT, 2018).

A second example in the same emirate of Abu Dhabi, equally managed by DCT, consists of what UNESCO classified as World Heritage in the desert city of Al Ain: the Cultural Sites of Hafeet, Hili, Bidaa Bint Saud and the Oases Areas, constituted by seventeen separate components, mainly archaeological remains, structured around the oases and the wider desert landscape. This serial property's coherence is defined by the formal, technical notions of authenticity, integrity, conservation, management, and so forth. Its relevance as a World Heritage site also integrates a wider notion of social coherence, namely its use for leisure purposes, by residents and visitors alike. For a recent, comprehensive overview of both local cultural heritage and urban development, see Caratelli et al., 2019). Some of the sites are difficult to reach, while others have been commodified with a notorious focus on community life. The most recent attraction is the Jebel Hafeet Desert Park, on a slope of the main mountain, offering camping, biking, horse riding and hiking activities, themed around an archaeological site. The Hili park is another good example of such an investment, with a diverse range of users, from local families to individual tourists. Two main levels may be discussed here. First, the resources themselves: located in opposite outskirts of the city, they have been packaged and promoted as a one-size-fits-all attraction, with an eye-catching website maintained by Abu Dhabi Department of Culture and Tourism. Other tourism components in Al Ain require a $4 \times 4$ vehicle and some off-road driving skills, but access to Hili, and now Hafeet, is easy. At the first location, some of the tombs and structures lay outside the large wall enclosing the park, but they are deemed of archaeological and scientific interest only, and have not been included in the tourism product. While not obstructing access, security guards at the gate inform this is a family location, pointing first and foremost at a community use.

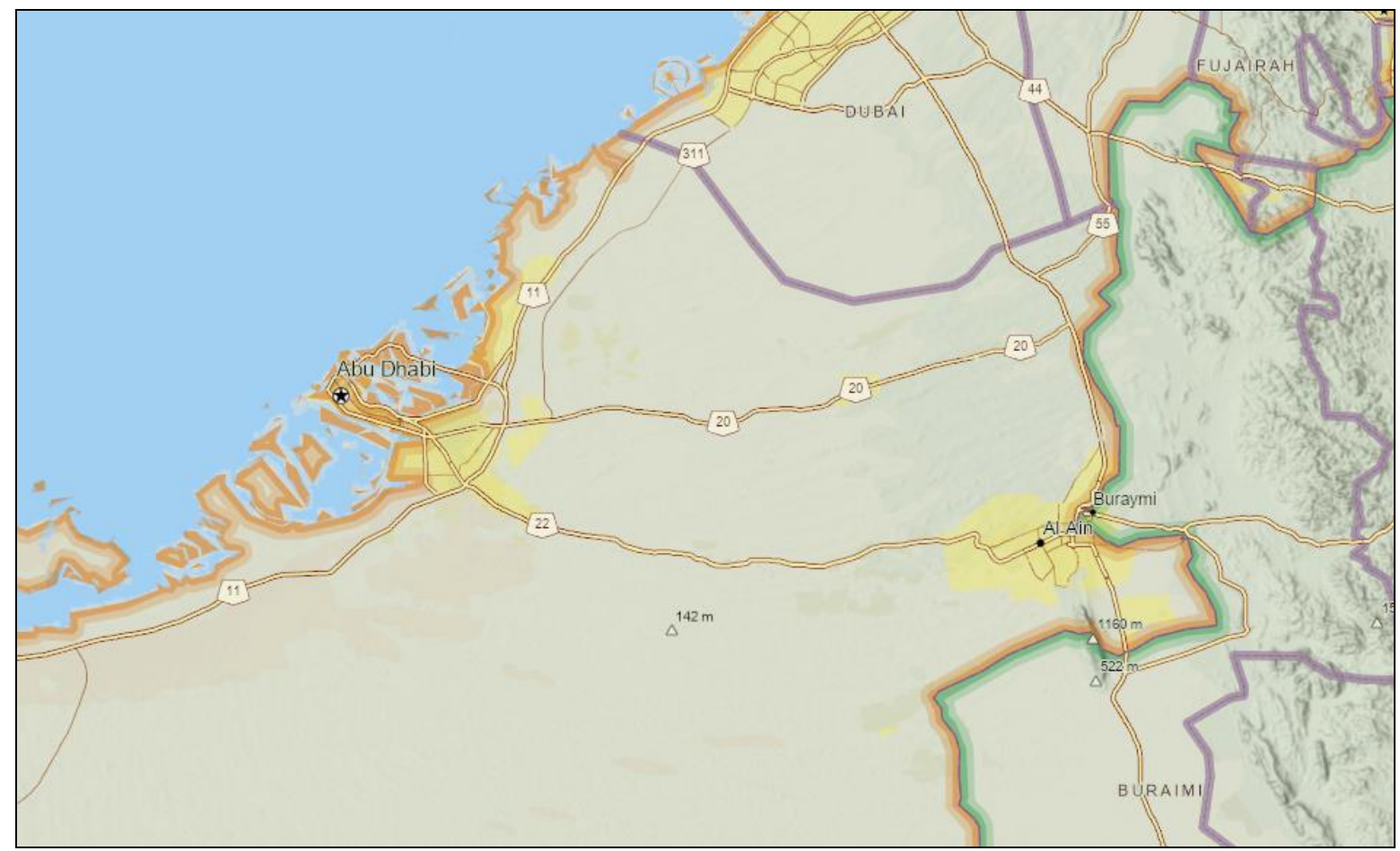

Figure 3. Northern part of the emirate of Abu Dhabi, @ ArcGIS

One can always discuss technical choices on conservation and restoration, yet the archaeological structures are relatively well preserved. They serve almost as a secondary element of a leisure park that includes a mosque and a children's playground. This again 
relates to the local user experience, Al Ain being the third largest city in the Emirates, with a population of about 700.000 . It differs from the close by coastal metropoles of Dubai and Abu Dhabi not only in terms of physical landscape, but also in a much larger proportion of Emirati nationals, about $50 \%$, and only a tiny minority of western expats. This is a huge cultural difference with Dubai, at only $1 \mathrm{~h}$ drive. So the way public leisure spaces are used is also distinctive, with more defined traditions shining through. On the other hand, first time visitors from elsewhere in the world expect something specific (and culturally rewarding) when heading for a location marketed as "Hili Archaeological Park", a main component of the World Heritage property. It is crucial to respect all types of consumers, who spend their time and money on the heritage of Al Ain instead of on something else.

\section{RESULTS AND DISCUSSION}

As indicated above, the application of a heuristic value criterion on the insularity and remoteness of both examples may gene rate a new theoretical perception. A first point to be made is fully epistemological in nature, and goes back to the issue of conceptual multiplicity. Islands do indeed not always need to be physically surrounded by water, and one finds many etymological examples of inland places called Ynys or Nisí, in Wales of Greece, for instance, or even the Île-de-France, the Parisian region that obviously is not an island either (Rackham, 2012). Ideas and social concepts on the matter are indeed much more fluid than strict taxonomic definitions would suggest. Pungetti (2016) provides a useful synopsis on the multiple categories to be considered, from oceanic to offshore and land bridge islands; Saadiyat would be classified as the latter, just as Venice, Copenhagen, or Taipa/Macao, which count on dry ac cess to the mainland. In addition, the same author defines island landscape identity as a combination of local values and traditions. Thi s inherently leads to the acknowledgment of potential cultural tourism resources, but attractiveness includes the many aspects of intangible desert heritage (Tremblay, 2006) that are required to provide solidity to an island-based product. An additional accelerator for theoretically densifying the cultural island metaphor is the concentration and combination of exclusive resources in a reduced area, e.g. the Saadiyat museums and their architects (Louvre/Jean Nouvel, Guggenheim/Frank Gehry, Zayed National Museum/Norman Foster). Such a constructed sociocultural insularity is however not equivalent to isolation, and some actual islands may even not be considered as such in an anthropological sense (Eriksen, 2007), when little distinction with the mainland is apparent in local lifestyle or in tourism.

Second, the dispersion of available factors and indicators produces equally fluid interpretations in terms of socioeconomic impacts. Market statistics on GDP, productivity, RevPAR, market penetration, and so on have non-linear applications when it comes to cultural tourism. To address the methodological question, namely insularity or arid remoteness not affecting access whilst adding to tourism robustness, a simple approach measuring tourism, on the one hand, and a multiplier effect, on the other, provides suggestive results, especially in the direct effects (about USD 43.3 billion nationally, that is $12.1 \%$ of GDP; MOFAIC 2020) but one needs to bear in mind one basic premise: the greater the local work and production, the larger the multiplier and its impact. In addition, for the current case study, leakages of spending are related to purchases occurred elsewhere, to produce and maintain the standard of quality services, either on the mainland (still intra-emirate though), or internationally (NYU and Louvre-related expenses, hotel chain logistics). The principle is that the development of Saadiyat's cultural district determined an increase in tourism investment on the island. Simply put, this impact becomes real as tourists spend both inside and outside of the museum. In practice, domestic visitor inputs do produce limited and biased spending estimates related to economic impact, as questionnaire responses (see Piekkola et al., 2014) tend to be very conservative, and because they would spend most of their money in the region anyway. Two main vectors need to be considered: direct spending, and increase in tourism activity generated by the museums; in other words, the impact of cultural on economic activity. In its first year, 2018, Abu Dhabi alone welcomed 10.27 million international visitors, and the Louvre just over one million in 12 months, according to its director (Chaigne-Oudin, 2019), of which $59 \%$ were tourists, against $41 \%$ of UAE residents. Visitor numbers are going steadily up, although the available time span since opening in November 2017 does not yet allow for statistically robust results. Figures for the end of 2018 add up to $1,259,000$ (DCT, 2018). Al Ain, on the other hand, offers just a fraction of those, with low density tourism and leisure dynamics (De Man, 2019b) that focus heavily on residential, returning visitors who seek green, sustainable areas (Yagoub, 2014). Only four 5-star hotels are available in Al Ain, which is a quite straightforward commercial indicator for demand; during Q4 2019, for instance, 1.165 million guests refer to Abu Dhabi, and 135.000 to Al Ain, according to official sources (WAM, 2020). All these numbers produce general orientations of market trends, and correlate demand with cultural factors, even though the articulation with other qualitative and emotional factors remains elusive.

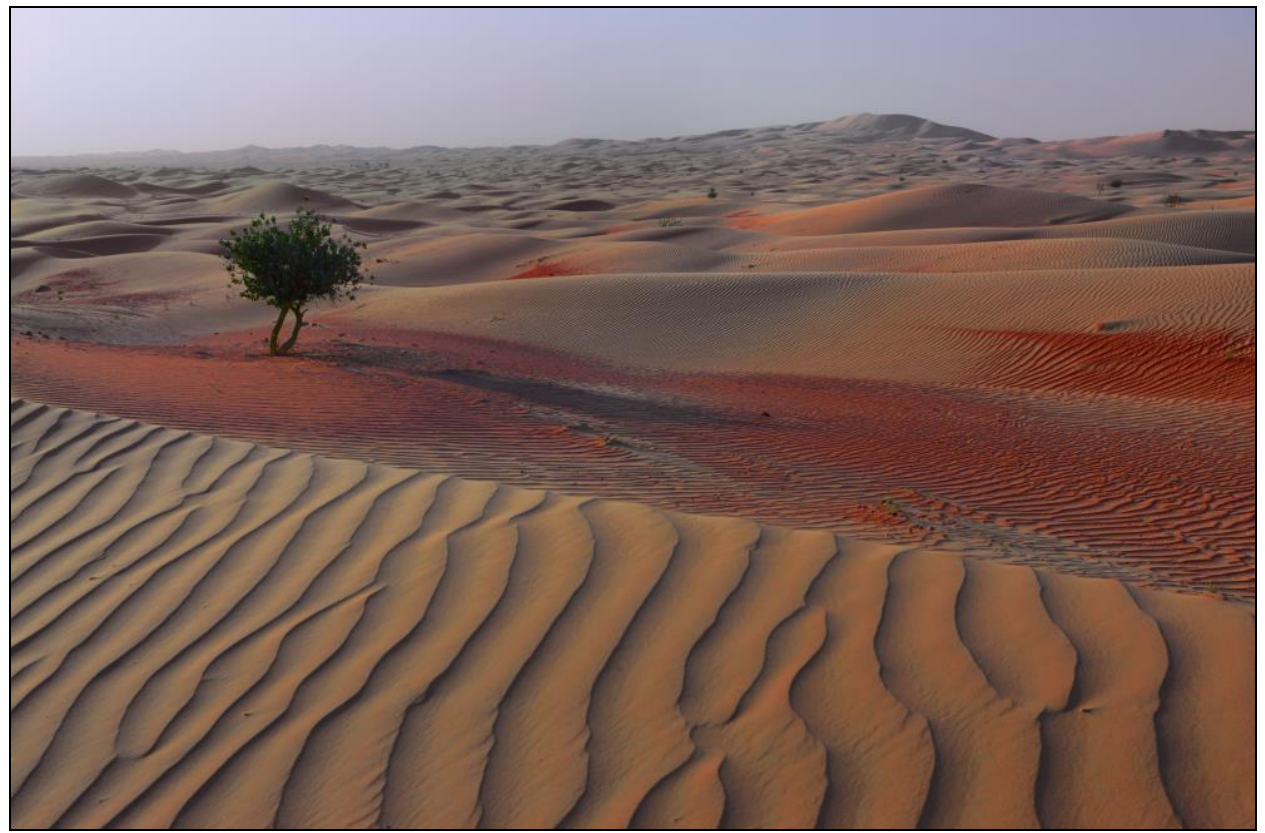

Figure 4. Al Ain red sand dunes (C Abu Dhabi Department of Culture and Tourism (Photography: Petra and Erik Hesmerg) 
This leads to a third point, namely the analytical disconnections between observing tourists and measuring the impacts they a re assumed to produce. One may question if or how the indicators above reflect actual cultural tourism activity, or even time spent locally. It is true that not all Saadiyat hotel users visit the Cultural District, and that a clear majority of museum visitors are not even hotel guests on the island. This is where the easiness of road access becomes a factor, as well as the proximity of other hotel units in a 30 -minute range. Driving inland to $\mathrm{Al}$ Ain, on the other hand, takes exactly 2 hours on the highway. It is a comfortable ride, certainly feasible for daytrips, amidst sand dunes. The main oasis represents a focal point in the middle of the urban tissue; as in Abu Dhabi city, road access is excellent, hence not a constraint. Indeed, an additional, enveloping factor providing cohesion is the natural landscape itself, ultimately converging towards a third component, viz. the marketing of a cultural experience. Investing in this requires not only developing a guiding premise, differentiating through products and services that capitalize on the local niches, but permanently adding value as well, and then achieving uniqueness in the mind of the visitor (Haywood, 2000). Whereas Al Ain projects a historical oasis theme, Abu Dhabi deploys distinctive options partly conditioned by its littoral environment, which allows for strong differentiating investments in relatively reduced areas such as Saadiyat. One quite recent example is a natural reserve based on a mangrove area that has been developed as a sustainable green program aiming at forms of ecotourism that may add density to the cultural centers.

This entire situation bears the question of whether the "islandness" of Saadiyat is indeed a competitive advantage. The possible answer is twofold, as first of all it constitutes a spectacular scenery with deliberate overspills between the strict boundaries of the cultural hubs, be it a museum (Louvre), an art centre (Manarat Al Saadiyat), or a campus (NYU) and, farther away, the involving waterl ine together with the exclusive infrastructures of beach clubs, golf courses, and luxurious hotels. The second part of the answer relates to both socio-economic and natural sustainability. It has been pointed out, on occasion, that westernized forms of commodification do not suit other geographies, and that insisting on this may create figurative islands as well. Some mega-investments could in theory create a sort of dissonance with local traditions, and result in dissociation or simply indifference. In the case of Saadiyat's Cultur al District, this is an unlikely outcome, as it is extremely well branded, engaging Emirati youth very directly, through educational outreach, art creation incentives, and social media, or in the field of direct employment, through implementing the Emiratization program set in motion by the government. As a result, what might have become a socially discriminating niche product has effectively broadened participation across segments, serving the entire cultural purpose of the district. A recent study (Hammad et al., 2017) integrates results on the perceptions of local tourism impacts, which demonstrated a significant difference between expat and Emirati residents of Abu Dhabi, on the a ssumption that tourism preserves the cultural identity of the UAE: locals agreed, but with a statistically much greater variance, that is, less clearly affirmative in numerical terms. Emiratis also believed more strongly that tourism causes inflation in property values, food, and cost of living. Such results may be interpreted in different ways (the high turnover among foreign residents is a plausible factor that comes to mind, as they lack a long-term perspective), and in fact the study shows a general alignment between the responses of both groups. In short, there is currently no significant disagreement on the impacts of cultural tourism, at least not between expats and locals.

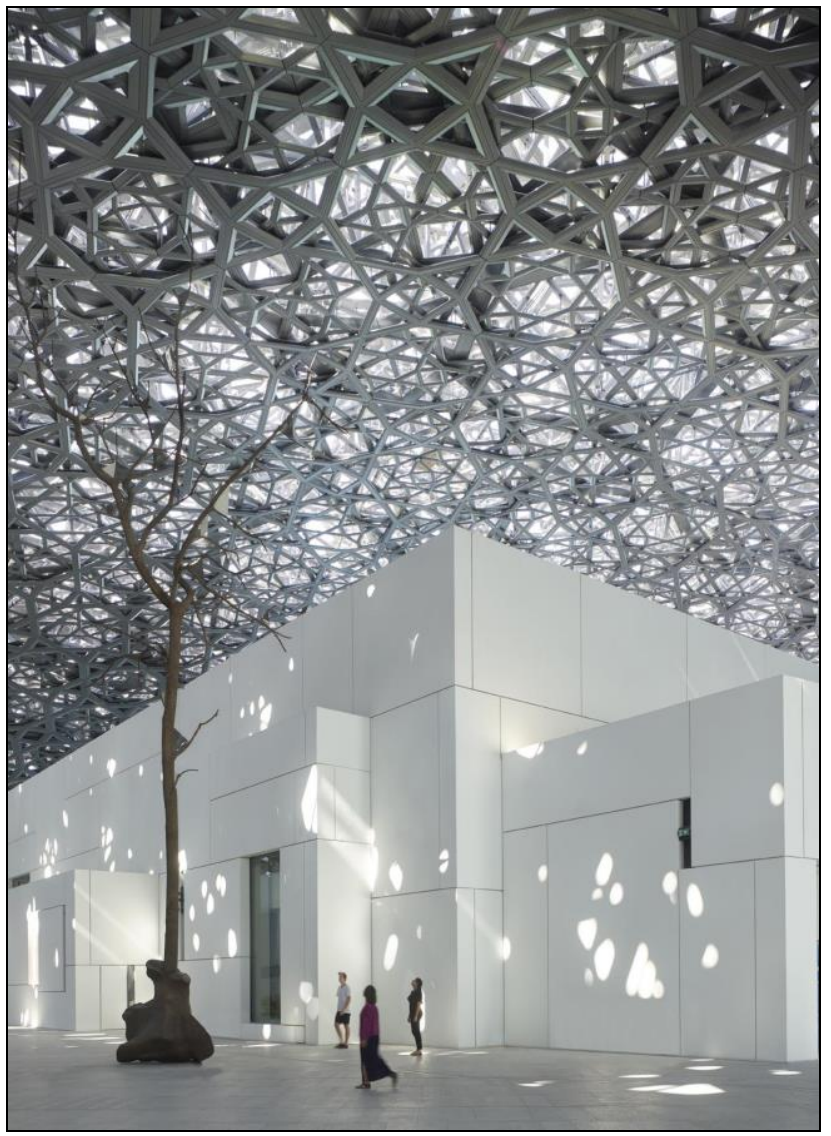

Figure 5. "Rain of light" effect under the Louvre Abu Dhabi's dome, inspired by the Al Ain Oasis (ㄷ Giuseppe Penone, Abu Dhabi Department of Culture and Tourism, Photography: Roland Halbe)

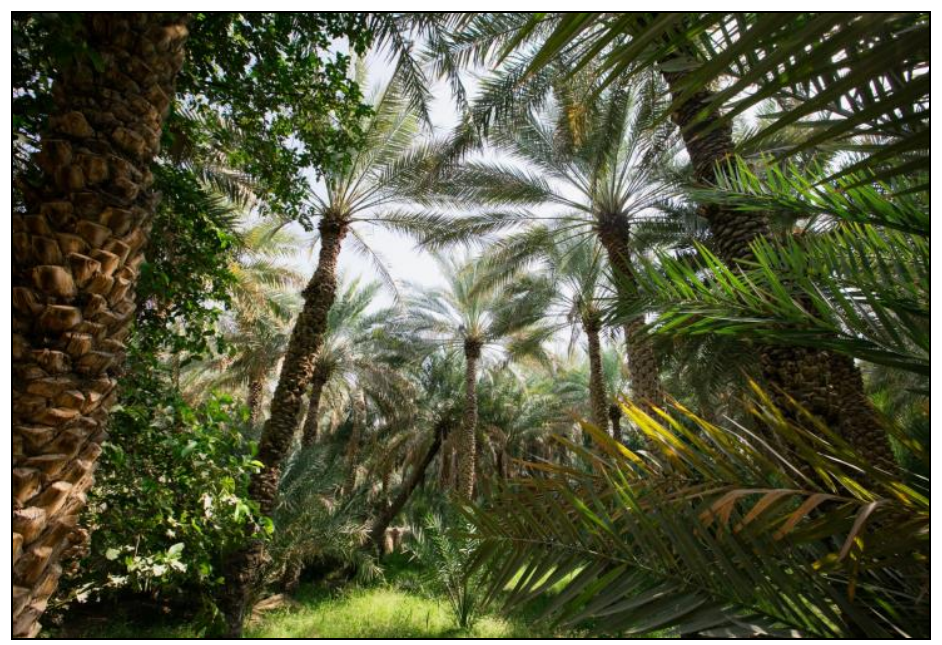

Figure 6. Sunlight shining through the

palm trees at the Al Ain Oasis (@Abu Dhabi Departmen of Culture and Tourism, Photography: Petra \& Erik Hesmerg)

The virtues of cultural investment for socioeconomic development constitute a truism that is empirically observable in destinations worldwide. However, a macroeconomic study by Du et al. (2016) serves as a warning that tourism does not grow to success in is olation, as it is dependent on entrepreneurial, innovative, creative stakeholders in the full range of civil society. Fragilities indeed lay in the lack 
of strong correlations due to the sheer nature of the tourism mix, and the absence of counterfactual scenarios. It always remains unanswered whether or not investment in other tourism and leisure infrastructures might have produced more interesting results. Many academic analyses also separate tourists from the environment they happen to physically spend time in, as if they were numbers in a linear equation, or pawns on a chessboard. Instead, they constitute an agency in the anthropological sense, in permanent interaction with their contexts and networks. This is actually a core element of what Franklin (2007) called "the problem with tourism theory", which looks for explanations for individual behavior rather than understanding the environment that makes tourism possible. Perhaps a good lens for analyzing Saadiyat island's potential is through Bourdieu (1984), and his concept of cultural capital, aggregating economy, culture, and social context. This means that the balance between culture and power determines one's integration in social groups, which on its turn develops hierarchies, differentiations, and creates economic capital for a place such as Abu Dhabi (Ajana, 2015). Economic investment, wellbeing and moral economy (Hesmondhalgh, 2016) are equally interesting to articulate in this context. These are of cou rse very conceptual approaches that provide ample food for thought.

\section{CONCLUSIONS}

One might conclude that, in the present case, insularity or desert remoteness are not functional deterrents, and not even comparatively more challenging to manage from an urbanistic standpoint. Instead, their appeal stems, as that of many other counterparts, from two converging and charismatic features: first, the tourism value of an island and an oasis is intrinsically higher, which means this perception is marketable; and second, even by car, arriving to both Saadiyat and Al Ain are scenic individual experiences. In the former case, either from the west, and over the Sheikh Khalifa bridge, or by taking the long Sheikh Khalifa Bin Zayed Al Nahyan highway from Yas island, over the smaller islands and inlets, surrounded by sandy beaches and mangroves. On its turn, the Abu Dhabi-Al Ain road provides a continuous, open landscape, and a corresponding emotional impression of deeply entering the desert. From such perspectives, the remote condition of Saadiyat and Al Ain become very enhanced, prompting awareness about exclusion or inclusion, and a unique setting for the cultural district and the World Heritage locations. In the case of desert destination marketing, the concept of ecotourism no rmally focuses the physical, geological territory, connected by the regional intangibles. This has commercial potential only in limited locations, and needs to take into account a number of issues that are hard to measure, such as latent negative impacts on the landscape, public perception, authenticity, or interpretation, to name a few. Both examples are converging case studies for heritage-based development, and constitute an important part of the national diversification strategy. Saadiyat island and the cultural sites of Al Ain provide rather different substrates for integrating a holistic tourism product, yet they function as comparable heritage components. Intercontinental tourism is a growing driver, in addition to resident staycation activity, as well as Emirati investment in the preservation of national heritage. In short, the combination of aridity and seeming remoteness stimulate a variety of emotional responses, hence establishing a setting for cultural tourism service providers. Throughout academic literature, this sort of multifactorial motivations seems to return to fairly essential factors, based on simple predeterminations and biases, on the supply side as much as on the consumers'.

This paper is being written during the global outbreak of the COVID-19 pandemic, which shall affect international tourism circuits and flows in ways currently impossible to predict. At this precise day, air traffic has started to reopen after being fully halted for months, yet tourism supply and demand remain heavily disturbed. The induced economic effects of this worldwide crisis on the travel and hospitality industries remain to be seen; it is however safe to say that resilience and quality will determine which cultural tourism destinations are to successfully reinvent themselves, and which are not. A major requirement here is to address the stereotypical assumptions taking tourism and economic growth in a linear relationship. While of course any revenue stemming from tourism is positive to the supplier, this does not spontaneously translate into a sustainable, systemic development. A narrow focus on tourism alone is therefore less effective than more diversified strategies, in which cultural tourism plays an interconnected part. From this standpoint, the two destinations discussed in this paper, Saadiyat and Al Ain, are representative of Abu Dhabi's diversity of resources and investment in economic diversification. They add complexity to what is otherwise often perceived as strict urban tourism, with special emphasis on hospitality and re tail, and perhaps less on heritage, which in fact is partly urban too. Monothematic tourism experiences are a thing of the past, but again the uncertainty of even short term post-pandemic consumer preferences does not warrant for any solid predictions.

\section{Acknowledgements}

The author wishes to kindly thank Rianne Norbart (DCT PR \& Communications Department), Kamilia Essa Mussalam (DCT Education \& Outreach Department), and Mariam Al Daheri (Louvre Abu Dhabi), for the photographs.

\section{REFERENCES}

Abuhjeeleh, M. (2019). Rethinking Tourism in Saudi Arabia: Royal Vision 2030 Perspective. African Journal of Hospitality, Tourism and Leisure 8(5), 1-16.

Abed, S., \& Matzarakis, A. (2018). Quantification of the Tourism Climate of Algeria based on the Climate-Tourism-Information-Scheme. Atmosphere 9(250), 1-18. https://doi.org/https://doi.org/10.3390/atmos 9070250

Agrusa, W., Lema, J., Tanner, J., Host, T., \& Agrusa, J. (2010). Integrating Sustainability and Hawaiian Culture into the Tourism Experience of the Hawaiian Islands. PASOS, Revista de Turismo y Patrimonio Cultural 8(2), 247-264. https://doi.org/http://dx.doi.org/10.25145/j.pasos.2010.08.018

Ajana, B. (2015). Branding, legitimation and the power of museums: The case of the Louvre Abu Dhabi. Museum \& Society 13(3), 322-341. http://dx.doi.org/10.29311/mas.v13i3.333

Al Hasni, Z. (2019). The Tourism Sector, its Importance in Achieving Economic Growth in the Sultanate of Oman. International Journal of Advanced Research 7(9), 331-335. http://dx.doi.org/10.21474/IJAR01/9666

Allan, M. (2016). Place Attachment and Tourist Experience in the Context of Desert Tourism - the Case of Wadi Rum. Czech Journal of Tourism, 5(1), 3552. http://dx.doi.org/10.1515/cjot-2016-0003

Baldacchino, G. (2006). Islands, Island Studies. Island Studies Journal 1(1), 3-18.

Bourdieu, P. (1984). Distinction: A Social Critique of the Judgement of Taste, Harvard University Press, Cambridge, USA.

Caratelli, P., Misui, M., \& El Amrousi, M. (2019). Al-Ain's Cultural Landscape: Identity, Innovation and Sustainability in a Challenging Economy. International review for spatial planning and sustainable development 7(3), 45-62. http://dx.doi.org/10.14246/irspsda.7.3_45

Carlsen, J., \& Butler, R. (2011). Island Tourism, Sustainable Perspectives, CABI, Wallingford, UK. http://dx.doi.org/10.1079/9781845936792.0000

Chaigne-Oudin, A.L. (2019). Interview with Manuel Rabaté, Director of Louvre Abu Dhabi, Les Clés du Moyen-Orient, 14 June.

Derderian, B. (2013). Producing Cultural Heritage: The Neoliberalization of Arts \& Cultural Spaces in Abu Dhabi's Souk and Sa diyāt Island. Arabian Humanities 2, 1-9.

De Jong, E. (2015). Culture and Economic Development. In International Encyclopedia of the Social \& Behavioral Sciences (pp 528-534). Elsevier, Amsterdam, The Netherlands.

De Man, A. (2016). Archaeological Heritage and Regional Development in Portugal. In Heritage Tourism Destinations: Preservation, Communication \& Development (pp. 142-153). CABI, Wallingford, UK. http://dx.doi.org/10.1079/9781780646770.0142 
De Man, A. (2018). Portuguese Heritage in the UAE: Authenticity in Archaeology and Tourism. In Innovative Approaches to Tourism and Leisure (pp. 3-15). Springer, Cham, Switzerland. https://doi.org/10.1007/978-3-319-67603-6_1

De Man, A. (2019a). Three Portuguese documents on the Arabian Gulf, with a commentary on trade and taxation. Liwa 21, 2-23.

De Man, A. (2019b). The Hili archaeological park (UAE): between World Heritage and local community attraction. In Sense and Sustainability, International Conference on Archaeology and Tourism (p. 61). Archaeological Museum, Zagreb, Croatia.

Du, D., Lew, A., \& Ng, P. (2016). Tourism and Economic Growth. Journal of Travel Research 55(4), 454-464. http://dx.doi.org/10.1177/0047287514563167

Elsheshtawi, Y. (2012). The Production of Culture: Abu Dhabi’s Urban Strategies. In Cities, Cultural Policy and Governance (pp. 133-144). SAGE, London, UK.

Eriksen, T. (2007). Do Cultural Islands Exist? Social Anthropology 1(1b), 133-147. http://dx.doi.org/10.1111/j.1469-8676.1993.tb00246.x

Exell, K. (2017). Utopian Ideals, Unknowable Futures, and the Art Museum in the Arabian Peninsula. Journal of Arabian Studies 7(S1), 49-64. http://dx.doi.org/10.1080/21534764.2017.1352163

Franklin, A. (2007). The Problem with Tourism Theory. In The Critical Turn in Tourism Studies, Innovative Research Methods (pp. 131-148). Elsevier, Oxford, UK. https://doi.org/10.1016/B978-0-08-045098-8.50014-3

Gnoth, J., \& Matteucci, X. (2014). A phenomenological view of the behavioural tourism research literature. International Journal of Culture, Tourism \& Hospitality Research 8(1), 3-21. http://dx.doi.org/10.1108/IJCTHR-01-2014-0005

Graci, S., \& Dodds, R. (2010). Sustainable Tourism in Island Destinations, Routledge, New York, USA. https://doi.org/10.4324/9781849776660

Haggag, M., \& Hadjri, K. (2005). The transformation of residential patterns in Al-Ain city, UAE. In UAE Sustainable development and planning II, vol. 1 (pp. 35-44). WIT Press, Ahshurst, UK.

Hammad, N., Ahmad, S., \& Papastathopoulos, A. (2017). Evaluating perceptions of residents' towards impacts of tourism development in Emirates of Abu Dhabi, United Arab Emirates. Tourism Review 72(4), 448-46. https://doi.org/10.1108/TR-03-2017-0046

Haywood, K. (2000). Revising and implementing the marketing concept as it applies to tourism. In Tourism Management, Towards the new Millennium (pp. 377-389). Pergamon, Oxford, UK. http://dx.doi.org/10.1016/0261-5177(90)90042-8

Hesmondhalgh, D. (2016). Capitalism and the media: moral economy, well-being and capabilities. Media, Cultura and Society 39(2), 202-218. http://dx.doi.org/10.1177/0163443716643153

Khawar, M. (2016). The Impact of Culture on Economic Growth and Development. International Advances in Economic Research 22(2), 245-246. http://dx.doi.org/10.1007/s11294-016-9579-7

Kleining, G., \& Witt, H. (2000), The Qualitative Heuristic Approach: A Methodology for Discovery in Psychology and the Social Sciences. Rediscovering the Method of Introspection as an Example. Forum Qualitative Social Research, 1(1), 13. http://dx.doi.org/10.17169/fqs-1.1.1123

Koşak, A. (n/d). A Short Essay on The Louvre Abu Dhabi. The Posible Reasons Behind "The Louvre Museum Franchising to the Desert”, Bilgi University, Istanbul, Turkey.

Leech, N. (2016). Saadiyat Island: the secret history, The National, 28.4.2016, 10.

McLeod, M. (2018). Developing a Network Analysis Methodology for Island Tourism Research. In Tourism Management in Warm-Water Island Destinations (pp. 178-191). CABI, Wallingford, UK. http://dx.doi.org/10.1079/9781786390929.0178

Modica, P., \& Uysal, M., (2016). Sustainable island tourism: competitiveness, and quality-of-life. CABI, Wallingford, UK. http://dx.doi.org/10.1079/ 9781780645421.0000

Parra López, E., \& Calero García, F. (2006). Agrotourism, sustainable tourism and Ultraperipheral areas: The Case of Canary Islands. PASOS, Revista de Turismo y Patrimonio Cultural 4(1), 85-97. http://dx.doi.org/10.25145/j.pasos.2006.04.006

Piekkola, H., Suojanen, O., \& Vainio, A. (2014). Economic impact of museums, Levon Institute / Vaasa University, Vaasa, Finland.

Podhorodecka, K. (2018). Tourism economies and islands' resilience to the global financial crisis. Island Studies Journal 13(2), 163-184. http://dx.doi.org/10.24043/isj.43

Poulin, T. (2010). An Oasis in the Desert? Issues and Intricacies Concerning the Louvre-Abu Dhabi Museum Expansion, Inquiries $2(2), 1$.

Rackham, O. (2012). Island landscapes: Some preliminary questions. Journal of Marine and Island Cultures 1, 87-90. http://dx.doi.org/ 10.1016/j.imic.2012.11.001

Sauvage, A. \& Gámez, A. (2013). Desarrollo, identidad cultural y turismo en los oasis de Baja California Sur, México. PASOS, Revista de Turismo y Patrimonio Cultural, 11(1), 159-172. http://dx.doi.org/10.25145/j.pasos.2013.11.010

Sharpley, R. (2002). The Challenges of Economic Diversification through Tourism: the Case of Abu Dhabi. International Journal of Tourism Research 4, 221235. https://doi.org/10.1002/jtr.378

Sharpley, R. (2012). Island tourism or tourism on islands? Tourism Recreation Research 37(2), 167-172. http://dx.doi.org/10.1002/jtr.378

Sorokina, E., \& Wang, Y. (2018). Theory building and evaluation in tourism research. In Handbook of Research Methods in Tourism and Hospitality Management (pp. 87-101). Edward Elgar, Publishing Cheltenham/Northampton, UK. https://doi.org/10.4337/9781785366284.00013

Tremblay, P. (2006). Desert Tourism Scoping Study, A report by Charles Darwin University, in conjunction with Curtin University for Desert Knowledge Cooperative Research Centre, Alice Springs.

Van Middelkoop, M., Borgers, A., \& Timmermans, H. (2003). Inducing Heuristic Principles of Tourist Choice of Travel Mode: A Rule-Based Approach. Journal of Travel Research, 42(1), 75-83. http://dx.doi.org/10.1177/0047287503254116

Webb, D. (2002). Investigating the Structure of Visitor Experiences in the Little Sandy Desert, Western Australia. Journal of Ecotourism, 1(2-3), 149-161. http://dx.doi.org/10.1080/14724040208668121

Yagoub, M. (2014). Parks in Al Ain, United Arab Emirates: Geographical Distribution, Opportunities, and Challenges. The Arab World Geographer 17(1), 24-41.

Yildirim, E., \& El-Masri, S. (2010). Master Planning for Conservation in Al Ain Oasis. In Proceedings of the 46th ISOCARP Congress (pp. 19-23). University of Nairobi, Nairobi, Kenya.

*** DCT (2018). Department of Culture and Tourism Abu Dhabi Annual Report. DCT, Abu Dhabi, UAE.

*** MOFAIC (2020). Travel \& Tourism, Ministry of Foreign Affairs and International Cooperation, Abu Dhabi, UAE.

*** STR (2019). Trend Report Middle East \& Africa, STR, Dubai, UAE.

*** WAM (2020). AED1.84 billion hotel revenues in Abu Dhabi in Q4-2019, 30.1,2020. 